\title{
The First Report of Small Cell Cancer of the Uvula Presenting With Ectopic Adrenocorticotropic Hormone Syndrome
}

\author{
Arjun Natarajan ${ }^{\mathrm{a}, \mathrm{b}}$, Ashraf Abugroun ${ }^{\mathrm{a}}$, Amir Khan ${ }^{\mathrm{a}}$, Numan Jahangir ${ }^{\mathrm{a}}$
}

\begin{abstract}
Small cell carcinoma ( $\mathrm{SmCC}$ ) of the head and neck is a rare occurrence. We herein present a case of a 62-year-old female who was diagnosed with small cell cancer of the uvula. The patient developed increased body swelling, elevated blood pressure, persistent hypokalemia and new onset diabetes mellitus. Further workup confirmed a diagnosis of Cushing's syndrome secondary to ectopic adrenocorticotropic hormone (ACTH) production. To our knowledge, this is only the second case of SmCC of the uvula described in literature, and the first associated with any paraneoplastic syndrome. By reporting this case, we aim to characterize the tumor clinical course and highlight the aggressive nature of its growth.
\end{abstract}

Keywords: Small cell cancer; Uvula; Ectopic; ACTH

\section{Introduction}

Small cell carcinoma (SmCC) of the head and neck constitutes a mere $0.3 \%$ of head and neck cancers in the United States [1]. Less than $5 \%$ of all SmCC are extra pulmonary, and of these only $11-16 \%$ cases are of the head and neck $[2,3]$. The most common site for head and neck SmCC is the larynx [1]. Paranasal, nasal cavity, and sinonasal are the other main sites, while oral and oropharyngeal $\mathrm{SmCC}$ remain rarely described in literature. SmCC is typically seen in males (3:1, male-female ratio), with a median age of occurrence $60-70$ years at time of diagnosis [4, 5]. Paraneoplastic syndromes like Lambert-Eaton myasthenia, SIADH, and Cushing's syndrome may be seen in these neuroendocrine tumors $[4,6]$.

To our knowledge, this is the second case of SmCC of the uvula described in literature and the first associated with

Manuscript submitted June 13, 2018, accepted July 10, 2018

${ }^{a}$ Department of Internal Medicine, Advocate Illinois Masonic Medical Centre, Chicago, IL, USA

${ }^{\mathrm{b} C}$ Corresponding Author: Arjun Natarajan, Department of Internal Medicine, Advocate Illinois Masonic Medical Centre, Chicago, IL 60657, USA.

Email: arjun.natarajan@advocatehealth.com

doi: https://doi.org/10.14740/wjon1130w any paraneoplastic syndrome. The lack of data suggests that our management for this condition is often based on strategies typically used in involvement of other head and neck sites.

\section{Case Report}

A 62-year-old female was referred to the hospital for evaluation of hypokalemia. A few weeks prior to admission, she developed sore throat and difficulty swallowing. She also had noticeable change in her voice where it became more nasal. The patient had observed increase in weight and generalized swelling. She had a past medical history of alcohol abuse, hypertension and chronic obstructive lung disease (COPD), and was a smoker since childhood. Her family history was significant for a brother who was diagnosed with nasopharyngeal cancer. The patient was evaluated by an otorhinolaryngologist (ENT) and had a laryngoscopy showing a uvular lesion. A CT scan of the neck showed $2.9 \mathrm{~cm}$ left-sided mucosal/submucosal mass in the upper pharyngeal wall/left nasopharyngeal wall suspicious for nasopharyngeal carcinoma, with multiple enlarged regional lymph nodes. Biopsy of the lesion in the oropharynx revealed small cell cancer of the uvula (Fig. 1). The tumor tested positive for synaptophysin and TTF-1. Tests for p16 and HPV were not performed. The patient was referred to the oncology clinic and on follow-up visit, she had shortness of breath and excess wheezing. Her initial laboratory workup revealed hypokalemia, and accordingly she was sent to the emergency department (ED).

Upon arrival, her vitals were stable. On physical exam, she had moist oral mucosa without pharyngeal erythema. Her uvula was enlarged but not obstructing the pharynx. She had no palpable cervical lymph nodes. Chest examination revealed limited air entry with mild expiratory wheezes with coarse breathing sounds. Heart sounds were regular without murmur. She had $1+$ lower extremity edema. Complete blood count $(\mathrm{CBC})$ showed white blood cells of $11.7 \times 10^{3} / \mu \mathrm{L}$, hemoglobin level $14.3 \mathrm{mg} / \mathrm{dL}$, platelet count of $123 \times 10^{3} / \mu \mathrm{L}$. INR was 1.2 . Serum procalcitonin level was $171.37 \mathrm{ng} / \mathrm{mL}$. Comprehensive metabolic panel (CMP) showed serum potassium $2.1 \mathrm{mmol} / \mathrm{L}$, sodium level $145 \mathrm{mmol} / \mathrm{L}$, normal blood urea nitrogen (BUN) and creatinine levels. Serum calcium level was $8 \mathrm{mg} / \mathrm{dL}$, magnesium level 2.1. There was mild transaminitis with AST 147 U/L, ALT $119 \mathrm{U} / \mathrm{L}$ and alkaline phosphatase $123 \mathrm{U} / \mathrm{L}$. Total bilirubin was $0.6 \mathrm{mg} / \mathrm{dL}$ and albumin level was $3 \mathrm{mg} / \mathrm{dL}$. Chest 


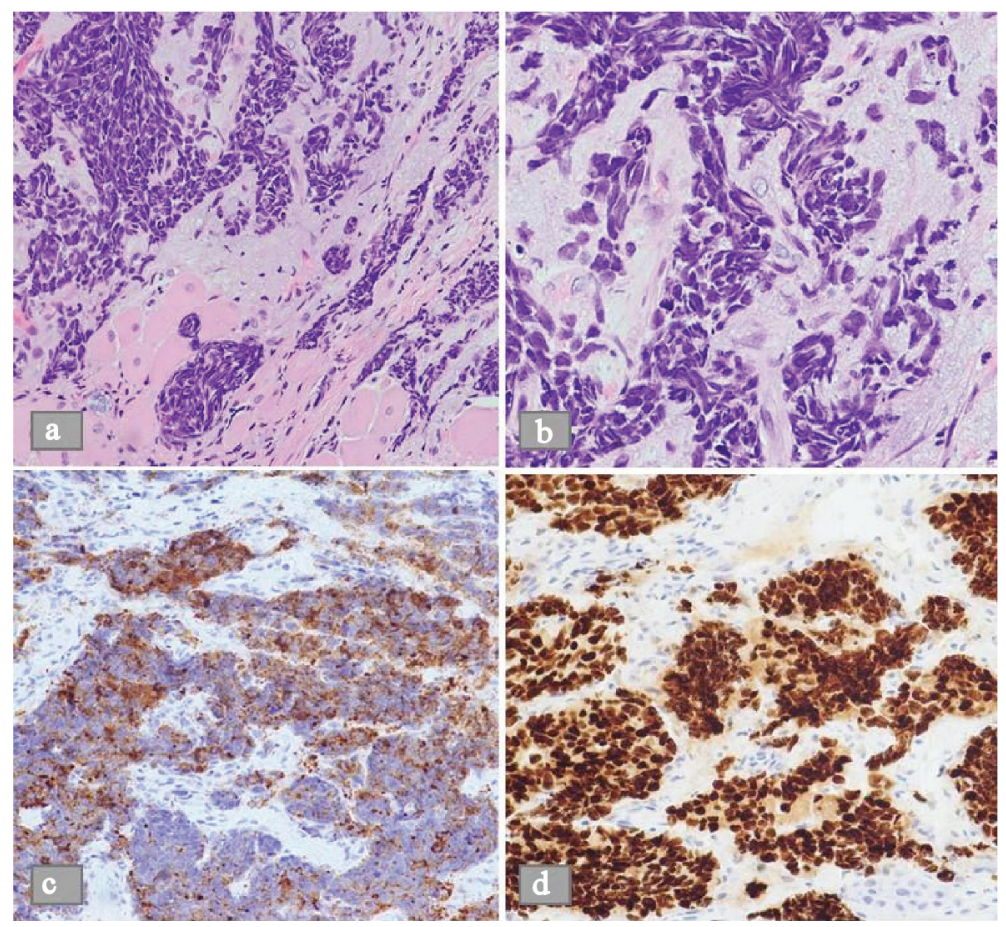

Figure 1. Microscopic view of a histological biopsy of the uvula. (a) H\&E stain shows sheets of spindle shaped cells in nests on low power microscopic view (b) H\&E stain shows the dense nuclei with inconspicuous nucleoli and scant cytoplasm on high power microscopic view. (c) Demonstrable positivity to synaptophysin stain. (d) Similar positivity to TTF1 stain.

X-ray showed hyper inflated lungs with coarse interstitial infiltrates along the right lung and left lower lung suggestive of atypical pneumonia. Computed tomography (CT) of the chest showed moderate emphysematous changes and infiltration suggestive of pneumonia without evidence of metastasis. Patient received azithromycin and ceftriaxone together with supplemental oxygen and bronchodilators. Magnetic resonance imaging (MRI) of the brain showed heterogeneous, mildly enhancing, T2 bright mass along the left fossa of Rosenmuller, compatible with her malignancy (Fig. 2). Enlarged bilateral retropharyngeal and cervical lymph nodes were noted. Nonspecific dural thickening and enhancement were concerning for malignant spread. Further diagnostic workup for tumor staging included CT scan of the abdomen which showed nodular cirrhotic liver with innumerable metastatic deposits within the liver measuring up to $3.2 \mathrm{~cm}$ (Fig. 3). A nuclear medicine bone scan showed no evidence of osseous metastasis. Though patient was not known to be diabetic, her admission hemoglobin A1c (HbA1c) was 6.4, and throughout her hospital stay, she was noted to be hyperglycemic with blood glucose rang-

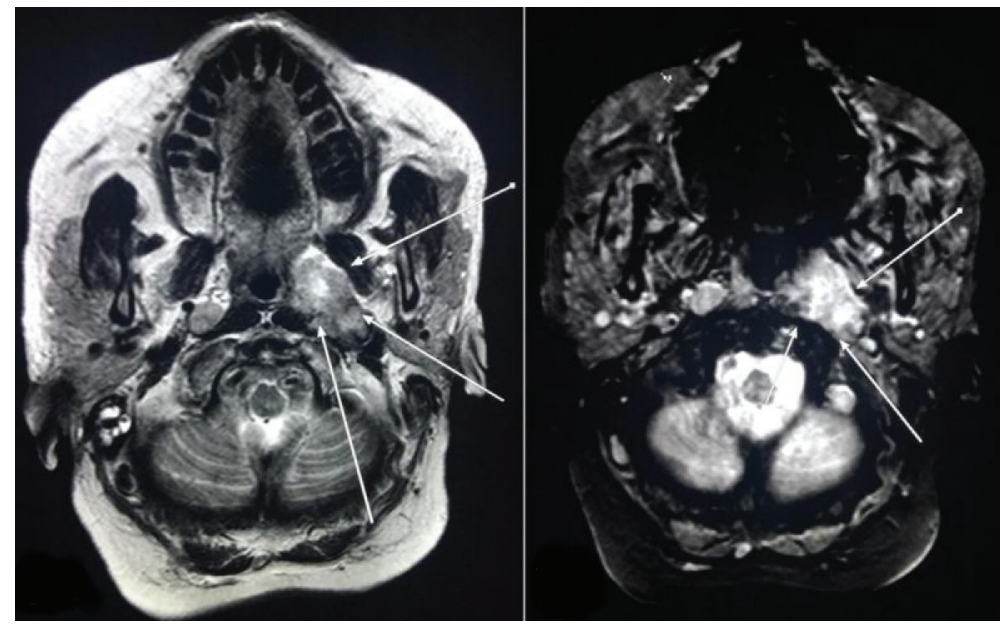

Figure 2. Magnetic resonance imaging (MRI) of the brain showed heterogeneous, mildly enhancing, T2 bright mass along the left fossa of Rosenmuller, compatible with malignancy (arrows). 


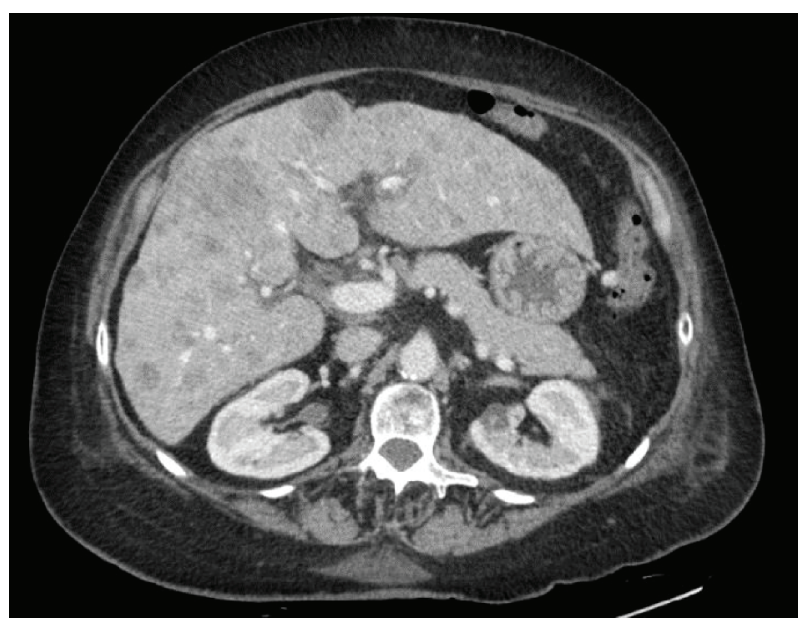

Figure 3. CT scan of the abdomen showed nodular cirrhotic liver with innumerable metastatic deposits within the liver measuring up to 3.2 $\mathrm{cm}$.

ing from 159 - $336 \mathrm{mg} / \mathrm{dL}$. She was also found persistently hypokalemic requiring frequent potassium supplementation. Accordingly, adrenocorticotropic hormone (ACTH) was requested and showed a level of $479 \mathrm{pg} / \mathrm{mL}$. Serum aldosterone level was $4.8 \mathrm{ng} / \mathrm{dl}$, and renin activity was $1.1 \mathrm{ng} / \mathrm{ml} / \mathrm{hr}$.

Patient was diagnosed with late metastatic small cell carcinoma of the uvula and she was determined to be a poor candidate for chemotherapy given worsening thrombocytopenia and generally poor condition. Palliative radiation was offered in view of dural metastases but the patient was not amenable to further treatment at this point. The patient decided in favor of comfort measures and was accordingly set up for home hospice care upon discharge.

\section{Discussion}

SmCC of the head and neck is a rare entity, which most commonly affects the larynx, nasal and paranasal sites [1]. Chief risk factors for SmCC appear to be tobacco, alcohol and environmental factors $[2,4,6]$. HPV infection is strongly associated with development of neuroendocrine tumors (NETs) in the head and neck [7-9].

Typically, SmCC is identified using hematoxylin and eosin with sheets and nests of round or spindle-shaped cells with dense nuclei, fine granular nuclear chromatin, inconspicuous nucleoli and scant cytoplasm. These tumors typically have a high Ki-67 index indicative of increased cell proliferation. In addition to tumor architecture, these SmCCs may express immunoreactivity to cytokeratin, chromogranin, CD56, synaptophysin and thyroid transcription factor-1[10]. HPV-associated SmCCs express immunoreactivity to p16 [7, 8]. Our patient was positive for synaptophysin and TTF-1 but was not tested for p16. CT imaging and indirect laryngoscopy are useful but nonspecific.

The association of paraneoplastic syndromes and neuroendocrine tumors is well established [4, 6]. Ectopic ACTH syndrome (EAS) is a rare cause of ACTH dependent Cushing's syndrome. It typically presents with hypertension, hypokalemia, hyperglycemia and severe metabolic alkalosis. There can be neuropsychiatric symptoms (most frequently depression and psychosis) in up to $50 \%$ patients $[11,12]$. The gold standard for diagnosis of EAS is bilateral inferior petrosal sinus sampling after CRH administration.

Recent data confirm SmCCs are rare, aggressive, and typically present in late stages III, IVA, or IVB and with distant metastatic disease $[1,2,13]$. Per multiple studies, approximately $50 \%$ patients tend to have lymph node positive disease at diagnosis $[1,13,14]$. SmCC of the head and neck appears to have a prognosis like small cell lung cancer (SCLC), especially comparable at extensive stages where overall survival is 10 - 12 months. Laryngeal SmCC has a poor prognosis as compared to paranasal and nasal cavity tumors. Sinonasal SmCCs tend to present as locally advanced as opposed to laryngeal and pharyngeal which are more often seen with distant metastases [1].

Management of SmCC of the head and neck is similar to that of SCLC, requiring a combination of radiation and chemotherapy. Management of localized SmCC of the head and neck previously involved surgery as well $[1,4,15]$. Recurrence rate tends to be high and distant metastases are common especially with cervical nodes involved. In non-metastatic disease, neoadjuvant, concurrent, or adjuvant chemotherapy (most commonly with cisplatin and etoposide) can be given to reduce tumor burden and reduce risk of metastasis. In metastatic disease, chemotherapy has been shown to prolong survival $[1,12$, 16]. However, in our case, the patient was not a good candidate for chemotherapy. Addition of surgery to combination of chemotherapy and radiotherapy does not prolong survival in locally advanced disease when compared to standard chemotherapy and radiotherapy regimen [1].

\section{Conclusions}

SmCC of the head and neck is rare, aggressive and associated with a poor prognosis. Among these, patients with oral or oropharyngeal involvement appear to have a slightly better prognosis with longer median survival. In patients with locally advanced disease, surgery does not significantly prolong survival.

\section{Acknowledgments}

To Dr. Rizwan Ahmed, from the Department of Radiology.

\section{References}

1. Pointer KB, Ko HC, Brower JV, Witek ME, Kimple RJ, Lloyd RV, Harari PM, et al. Small cell carcinoma of the head and neck: An analysis of the National Cancer Database. Oral Oncol. 2017;69:92-98.

2. Renner G. Small cell carcinoma of the head and neck: a review. Semin Oncol. 2007;34(1):3-14. 
3. van der Heijden HF, Heijdra YF. Extrapulmonary small cell carcinoma. South Med J. 2005;98(3):345-349.

4. Mills SE. Neuroendocrine tumors of the head and neck: a selected review with emphasis on terminology. Endocr Pathol. 1996;7(4):329-343.

5. Procopio G, Ricotta R, Fusi A, Celio L, De Dosso S, Catena L, Ferrari L, et al. Neuroendocrine tumors of the larynx: a clinical report and literature review. Tumori. 2006;92(1):72-75

6. Overholt SM, Donovan DT, Schwartz MR, Laucirica R, Green LK, Alford BR. Neuroendocrine neoplasms of the larynx. Laryngoscope. 1995;105(8 Pt 1):789-794.

7. Misawa K, Kawasaki H, Matsuo R, Sugiyama K, Mochizuki D, Endo S, Imai A, et al. Human papillomavirus-associated small cell carcinoma/neuroendocrine carcinoma of the oropharynx: a report of two cases. Springerplus. 2016;5(1):1847.

8. Bates T, McQueen A, Iqbal MS, Kelly C, Robinson M. Small cell neuroendocrine carcinoma of the oropharynx harbouring oncogenic HPV-infection. Head Neck Pathol. 2014;8(1):127-131.

9. Evsei A, Iosif C, Enache S, Manea C, Sarafoleanu C. Primary small cell carcinoma of the larynx: report of a rare tumor. Case Rep Oncol Med. 2011;2011:978676.

10. Ferlito A, Silver CE, Bradford CR, Rinaldo A. Neuroen- docrine neoplasms of the larynx: an overview. Head Neck. 2009;31(12):1634-1646.

11. Martinez-Valles MA, Palafox-Cazarez A, Paredes-Avina JA. Severe hypokalemia, metabolic alkalosis and hypertension in a 54 year old male with ectopic ACTH syndrome: a case report. Cases J. 2009;2:6174.

12. Ilias I, Torpy DJ, Pacak K, Mullen N, Wesley RA, Nieman LK. Cushing's syndrome due to ectopic corticotropin secretion: twenty years' experience at the National Institutes of Health. J Clin Endocrinol Metab. 2005;90(8):49554962.

13. Hatoum GF, Patton B, Takita C, Abdel-Wahab M, LaFave K, Weed D, Reis IM. Small cell carcinoma of the head and neck: the university of Miami experience. Int J Radiat Oncol Biol Phys. 2009;74(2):477-481.

14. Aguilar EA, 3rd, Robbins KT, Stephens J, Dimery IW, Batsakis JG. Primary oat cell carcinoma of the larynx. Am J Clin Oncol. 1987;10(1):26-32.

15. Mills SE, Cooper PH, Garland TA, Johns ME. Small cell undifferentiated carcinoma of the larynx. Report of two patients and review of 13 additional cases. Cancer. 1983;51(1):116-120.

16. Baugh RF, Wolf GT, McClatchey KD. Small cell carcinoma of the head and neck. Head Neck Surg. 1986;8(5):343354. 